\title{
Fundamentalization and Professionalization of Learning Content under the Competence Approach
}

\author{
Yulia I. Nikitina ${ }^{1}$, Svetlana M. Konyushenko ${ }^{2}$, Elena A. Kuzina ${ }^{3}$, Tatyana V. Afanasyeva ${ }^{3}$, Tatyana M. \\ Kozhanova $^{3}$, Raisa I. Platonova ${ }^{4} \&$ Ramil H. Mingazov ${ }^{5}$ \\ ${ }^{1}$ Kazan State Medical University named after S. V. Kurashov, Kazan, Russia \\ ${ }^{2}$ Immanuel Kant Baltic Federal University, Kaliningrad, Russia \\ ${ }^{3}$ Chuvash State Pedagogical University named after I. Y. Yakovlev, Cheboksary, Russia \\ ${ }^{4}$ North-Eastern Federal University named after M. K. Ammosov, Yakytsk, Russia \\ ${ }^{5}$ Kazan (Volga region) Federal University, Kazan, Russia \\ Correspondence: Yulia I. Nikitina, Kazan State Medical University named after S. V. Kurashov, Butlerova Street, \\ 49, Kazan, 420055, Russia. E-mail: frau.levina2010@yandex.ru
}

Received: April 16, 2015 Accepted: April 26, 2015 Online Published: May 28, 2015

doi:10.5539/jsd.v8n3p155 URL: http://dx.doi.org/10.5539/jsd.v8n3p155

\begin{abstract}
The purpose of this paper is aimed at studying the issue of formation of learning content based on its fundamentalization and professionalization under the competence approach. The presented paper demonstrates the process of professionalization and fundamentalization of training as a conceptual framework of shaping the content of disciplines in higher education. The basis of the presented work is the ideas of the competence approach, theory of fundamentalization and professionalization of vocational education. The paper presents the principles and mechanisms of fundamentalization and professionalization of the discipline's content and the algorithm of formation of fundamental and applied discipline content under the competence approach. This article is intended for teachers, researchers, heads of educational institutions involved in the formation and selection of the content of disciplines in higher education.
\end{abstract}

Keywords: higher education, competence approach, fundamentalization, professionalization, learning content

\section{Introduction}

\subsection{Background}

The accession of Russia to the Bologna process is the increased use of the competence approach for the training of highly qualified professionals to meet the requirements of the modern labor market. Competence-oriented education is aimed at achieving planned ultimate goals of the education - competences, that is reflected in the Federal State Educational Standards of the third generation..

The development of the competence approach is determined by the following factors: the emergence of a new type of economy determining the need for changes in requirements to the quality of graduates training, the content of labor and professional activities; rapid development of information technology; increasing priority of creative aspects of professional and intellectual capacity of specialists; dynamics growth of professions' modification.

The introduction of competence approach will seriously affect all components of the learning process and will require substantial reconsideration of curriculum, teaching methods and traditional control - evaluation systems. In assessing the quality of educational achievements of vocational education graduates there comes forward not the amount of learned knowledge or reproduction algorithms based on samples, but key competences, creative approach to solving educational and life problems, ability to acquire knowledge independently and apply it in situations that are close to future careers.

\subsection{Status of a Problem}

Current trends of modern higher education in the world are characterized by its increasing practice-oriented character. This fact is explained by the desire of universities to prepare professionals being able to adapt, as soon 
as possible, to rapidly changing conditions of professional activities, new information technologies and communication systems, which have penetrated and become an integral part of any modern profession. Formation of competences, aimed at ensuring the future professional activity, requires only professionally directed knowledge and skills, that is in conflict with the need to develop the foundations of objective knowledge, basic concepts and phenomena, the study of the fundamental principles and laws, and forms a mosaic pattern of information among the students. This aspect defines an organization of the learning process, when cutting time of discipline acquirement, it is necessary to include fundamental and applied data and knowledge unjustly derived from the content of the discipline.

Fundamentalization issues involved such researchers as Basharin V. F., Elgin L. S., Kondratyev V. V., Mukhametzyanova G. V., Novikov A. M., Subetto A. I., Sukhanov A. D., Chitalin N. A. (Basharin, 1993; Elgin, 2000; Kondratiev, 2001; Mukhametzyanova, 2002; Novikov,2007; Subetto, 1995; Sukhanov,1996; Chitalin, 2005).

Professionalization, professional orientation, professional skills, professional activity, interdisciplinary skills were investigated by (Vlasenko, 1981; Vorobyov, 1973; Gutorov, 1977; Dyachenko, 1986; Izmailov, 1982; Koldenkova, 1977; Kudryavtsev, 1981; Kuzmina, 1970; Ledneva, 1990; Makhmutov, 1985; Tkachenko, 1979).

However, fundamentalization of vocational training of a specialist in the logic of competence approach, the integration with the professionalization of training is not enough disclosed in modern research. This condition requires improving the methodology and strategy of selection and structuring of content, methods, organizational forms and means of education corresponding to tasks of mobile specialist training, who possesses a complex of professionally important qualities useful in modern conditions.

\subsection{The Research Hypothesis}

For fruitful and constructive professional activity of a future specialist in every field it is required a high level of training for practical and rationalizing work. The competence model is a description of what combination of competences should have a specialist to perform any professional functions, what should be the level of his/her training. Therefore, when designing the training, fundamentalization and professionalization are becoming particularly important. The inclusion of fundamental knowledge in holistic training will enable university graduates to fulfill effectively social and professional functions, upgrade the skills continuously, master the related specializations, this is especially relevant in rapidly changing techniques and technologies.

\section{Materials and Methods}

\subsection{Criteria of Fundamental Knowledge}

The definition of the concept - knowledge "fundamentalization"- is based on the analysis of pedagogical researches. The education orientation on studying deep, essential, system forming basis and relationships between the various processes of the world is a system characteristic of the fundamental education. Fundamental knowledge is changing relatively slow and remains relevant over the average period of person's employment history, and provides an opportunity to form the basis of one's own knowledge and skills. Fundamentalization of training involves selection of the most meaningful and sustainable content, which can be used as a guide in practice. It's about knowing the basic principles, laws that allow a proper assessing of the possibility of applying the newly acquired knowledge.

Subetto A.I. (Subetto, 1995), highlighting as a criterion the problematic knowledge, classifies fundamental nature of scientific and rational knowledge and scientific situation; fundamentalization disciplinary content varies depending on the level of education, access to the laws of functioning, the core of which is the reflexive knowledge, meta-knowledge; universality, focus on the perception of the world as a whole.

Basharin V.F. (Basharin, 1993) considers fundamental knowledge as a "universal, intellectual power that allows one to dive easily into new activities, to adopt and acquire another profession". Therefore they are united for a variety of professional activities and mobile with respect to transfer from one area of activity to another, and create the capacity to absorb a whole range of close specialties.

Thus, the fundamental knowledge of future specialists provides an opportunity to move up the educational stages and build individual educational trajectory. Fundamentalization is a process that helps to create a unified picture of the world and the growth of the intellectual opportunities of a personality, this process provides a high level of education. Implementation of the fundamentalization is in formation a base for professional polytechnic and general culture, labor mobility and creativity of students. 


\subsection{The Concept of Learning Content Professionalization}

At the stage of professionalization they need to focus on such important qualities as a social and professional competency, the need for self-improvement, professional dominance and social responsibility, prognostic ability, professional reliability and civic humanism, professional intelligence and individual style of activity.

This will require the professionalization of education, refinement, that is:

- definition of the leading objective of each discipline, its place in the knowledge system formation during the training of specialists at universities;

- identification of the most significant professional problems solved on the basis of the knowledge obtained in each discipline;

- taking into account the appropriate structure of the discipline, the share of its each part;

- development of practical knowledge and lessons aimed at creating system professional knowledge.

Professionalism of any specialist should be considered as an integrated marker of its personal-activity essence, while distinguishing three components: knowledge as a foundation, a basis of professionalism in general, describing its personal and activity essence; communication as an ability and willingness to use the knowledge in terms of decision-making and analysis of the situation; self-improvement as a strategic skill in professional formation and development, which is achieved through self-education, as well as in the process of communicating with colleagues and manifests itself as the ability to see the advantages and disadvantages of one's own activities, to eliminate quickly through self-education and self-development.

\subsection{The Concept of Fundamentalization and Professionalization of the Vocational Education Content}

Fundamentalization process and the process of professionalization are inherently opposed, but they are not only interrelated, but also complement and enrich each other (Kuznetsov, 1994). This is described logically in the concept of multilevel fundamentalization of vocational training content, which was taken as the theoretical basis of our research (Chitalin, 2005).

Since the core representations in various subject areas remain relatively unchanged, they are called invariant.

The education system cannot provide all kinds of variability of human activity, and is based on a common cultural and information space surrounding the person. In the construction of the education content it is important to highlight common (fundamental) invariants, which will help to avoid overloading the curriculum. In this case, the information capacity of such programs is rather increased than reduced, as the assimilation of invariant knowledge allows students to apply it independently in different situations. On the basis of invariants as backbone components they should build the whole learning content.

It is important to start composing the content from highlighting the main core concepts. Location of the studied material should be such that all subsequent material follows from the preceding one and becoming its development, but would not constitute completely new knowledge. The study of concepts must be implemented in such way that, first of all, there have been distinguished their most general, fundamental properties, and for this purpose it is necessary to start learning from the main and general things, not from the elements, but from the structure. Distinguishing of the general principles and basic concepts allows us to create on them, as on sticks, the structure of the studied discipline. Basic concepts perform the role of the knowledge "generator" in the curriculum. Their distinguishing contributes not only to the theoretical enrichment, but also to regulation of the entire conceptual structure of educational material. Distinguishing of the leading concepts provides an opportunity to present the material scientifically, from a single view point and to rethink the already known facts from a general standpoint. Using this approach, it is possible to lay the foundations of the whole system of knowledge, to reveal the internal connections and relationships of the basic concepts, to show their manifestation on the concrete facts and phenomena of reality. The considered approach allows us a better understanding of the studied material since generates a structure that interacts much closer with new knowledge than individual facts. The more links can be established between the new and existing knowledge, the deeper and broader the understanding of new material, and the better it will be acquired.

In the context of Russian education modernization, special attention should be paid to the fact that fundamentalization of education should be aimed at training people being able to find and make responsible decisions independently, on the basis of core and system forming knowledge, in conditions of uncertainty and critical stress situations, when a person faces new, complex natural and social problems.

Targeting the learning process on the ability to apply the acquired knowledge in practice is typical for the competence approach. The purpose of the competence training is to develop not only knowledge and skills, but 
also such personal qualities (competences), which provide the ability and willingness to use the developed knowledge and skills in practical activities (competency).

\section{Results}

\subsection{The Algorithm of Formation of the Discipline's Fundamental and Applied Content under the Competence Approach}

The modern fundamental training should be carried out taking into account the context of learning. One can understand why logical but isolated from the activity the learning content does not contribute to qualitative fundamental training, on the basis of psycho-pedagogical analysis conducted by A.A. Verbitsky (Verbitsky, 1998). Speaking about the formation of knowledge, he notes that the educational information as a foundation of knowledge cannot become the property of the individual, i.e. the knowledge itself, that has personal meaning for the person, that is a guide for action, expresses his attitude to the world, to society, to other people and to oneself. The context of life and activity, the context of professional future fills educational and cognitive activity of students with personal meaning, determines the level of their activity, a degree of involvement in the processes of learning and transformation of reality. If the student does not see the personal meaning in learning information, so the knowledge will be transformed into a formal, shallow, fragmented and fragile one instead of being transformed in student's mind into the system forming knowledge.

Transferring the basic laws, contained in the concept of fundamentalization, on the disciplines' content it is becoming clear that its content theoretically consists of scientific and fundamental, applied fundamental (techno-fundamental, technological-fundamental) and vocational fundamental components.

According to the concept of multilevel fundamentalization of vocational training the sequence of revealing the fundamental and applied content of a discipline comprises the following steps:

- definition of the scientific-fundamental component, namely: the fundamental phenomena, concepts that are the basis for understanding the various subject processes, bases of systems and their properties, that contribute to the formation of a common culture and world view;

- definition of the applied-fundamental component: knowledge and skills that help to understand the ways of solving problems in this area (solving of mathematical, physical, chemical and other problems), equipment setup, generalization, systematization and classification of concepts, analysis and synthesis of information (for humanities);

- definition of the professional-fundamental component: information about the possibilities of applying acquired knowledge and skills in their professional activities.

The issue of division of fundamental and applied knowledge, skills and abilities for any discipline is very debatable. Two viewpoints come to confrontation: the discipline unity, which gives to future specialists the fundamental scientific training and the creation of a specialized discipline focused exclusively on the profession. The basic concepts of this problem are presented in the writings of Fabrikant V.A. (Fabrikant, 1978). In his opinion, any science can be built on a rational model of the information structure, where the scientific information is divided into "core" and "shell". The "core" is changing relatively slowly with time, and the "shell" is converted quickly. In this regard, the base of any discipline should consist of materials of "core" information. Information included in the "shell" should be included in small proportions for illustrating "core" materials.

\subsection{The Example of Fundamentalization of Learning Content for the Discipline "Physics, Mathematics" in the} Medical University

On the basis of the research (Shapiro, Kowalski, 1989) let's define the types of relationships of discipline sections with special knowledge: 1) the basic theory of physics is illustrated by examples of theory application in the profession; 2) some physical common factors and laws derived from the examples of the profession; 3) after the derived physical laws there are given examples of their work in the professional field.

Basing on these types of relationships and specifying them for the discipline "Physics" in the medical university we highlight the following areas:

-physical analysis of phenomena and processes occurring in the organism;

-formation of generalized physical-biological concepts that have worldview significance;

-application of equipment in medicine with an understanding of the scientific-technical principles of its work;

- getting acquaintance with physical methods of research, diagnosis and treatment of humans. 


\subsection{Specific Features of Learning Content Professionalization under the Competence Approach}

Professionalization of the content of any discipline is a complicated process, which brings its own characteristics in the educational process and requires special training and efforts of the whole teaching staff. We have identified 4 stages of professionalization of education: 1) at the first stage it is important to establish connection between departments through getting acquaintance with their work and learning programs (with general scientific, general professional and special departments should study the work programs of basic disciplines and fix their recommendations to discipline content); 2) at the second stage the structure-logic scheme of interdisciplinary connections is being composed based on existing methodological and didactic developments, that is a clear reproducing of basic discipline sections with other disciplines; 3 ) at the third stage the construction of the basic discipline's work program is realized, which is based on the selection and including of the necessary material from the previously prepared structure- logic scheme. The basic requirement for the updated content design is its optimal structure and allocation of necessary professional and cultural competences; 4) at the fourth stage the pedagogical tools for the implementation of the professionalization of basic discipline's content are selected. This stage of the work involves distinguishing of levels, methods, techniques and organizational forms for the professionalization of certain sections of the discipline content.

For the foregoing reasons, we make the following generalizations on the professionalization of the basic discipline content:

- $\quad$ in the context of the professionalization of the discipline content one must always be aware of the logic of science itself, the sequence and the relationship of its elements;

- professionalization of the discipline content must be adjust in the work and educational curriculum of a discipline;

- the effective professionalization of the discipline content is provided by the integration of two approaches: 1) deepening of the material sections of the discipline itself without the inclusion of general and special disciplines material; 2) expansion of the discipline material, including special knowledge and illustrations from professional activities.

- there are different degrees of professionalization that demonstrate the depth of implementation of special knowledge into the discipline content;

-there is a number of forms of professionalization of the basic discipline content: the illustration of its application in future professional activities follow after the basic theory; after the basic theory it comes the comparison and the projection of this theory on the future professional activities; some laws, common facts and basic theory concepts are derived with the help of a system of specialized objects; composing and solution of problems with the professional content.

\subsection{The Example of Professionalization of Learning Content for the Discipline "Physics, Mathematics" in the Medical University}

We have identified three levels of professionalization of the content for the discipline "Physics, Mathematics":

1) the factual level aimed at increasing of students motivation for learning a specific section of the material. Namely, the basic physical theory is illustrated and concretized by special knowledge. This is being realized by attracting the additional material in the form of numerical data, examples, etc.;

2) the theoretical level, allowing a deeper review of the application of the gained knowledge in professional medical practice. For example, in studying the section "Hydraulics" theoretical level of professionalization is realized when, after the general physical theory of fluid flow, specific questions of flow in the blood vessels and capillaries, etc. are considered. The implementation feature of the theoretical level is the integration of each section of discipline content "Physics, Mathematics" with special knowledge. For this purpose the students are required additional mental efforts, the ability to match the material of different disciplines, understand and analyze the nature of the phenomena. This level of professionalization of the discipline content "Physics, Mathematics" increases the creative potential of students, the need for self-education in the discipline and in a professional activity.

3) the practical level is aimed at developing certain practical applied knowledge and skills that are required in the professional medical activity. At this level, it is used not only the material showing possibilities of applying the acquired knowledge and skills, but also the practical activities of students designed to prepare them for the use of acquired knowledge and skills in a professional medical practice. For example, on the practical level the professionalization of the discipline content "Physics, Mathematics" includes special physical methods for 
studying biological objects, basic operations on professional medical equipment.

While analyzing these levels of professionalization of the discipline content "Physics, Mathematics" one can see that higher levels include more simple. The sections of the discipline "Physics, Mathematics" can be professionalized at various levels. So for example, the section "the principle of amplifiers operation," can be seen only from the physical point of view: to study the work principle of the amplifier, its scheme, parameters and characteristics. The professionalization of this section on a factual level, after basic physical theory should be described the use of amplifiers in medicine (increase of biological signals of electrical and non-electrical nature and their transformation into an electrical signal). Further it is possible to illustrate the principle of operation of amplifiers on specific devices, such as electroencephalography, electrocardiography, etc. On the theoretical level, it is already required the study of the amplification theory of specific biological signals, that is, the balance of specific parameters of biological signals and amplifiers. On the practical level, it is provided the acquisition of the skill of amplifiers use for registration of biological signals.

\section{Discussions}

Taking all the aforesaid into consideration we can conclude that the integration of the two processes of fundamentalization and professionalization form a general principle of fundamentalization and professionalization, which is used to optimize the content of the discipline "Physics, Mathematics" in order to develop professional and general cultural competences of future doctors. It should be noted that this principle can be implemented in the educational process in different ways using a variety of organizational forms and methods.

The principle of fundamentalization and professionalization is a system forming one and determines the process of improving the basic disciplines content as an integral component of the professional education. This principle makes it possible to achieve the optimum balance of the fundamental and professional components of the basic disciplines content integrity, provides a harmonious vocational training, efficient formation of competences of future specialists.

\section{Conclusions}

Orientation of education to the personal interests, the formation of personality's competency, development of creativity and general culture are the priorities of the education reform. Approaches and ideals of a system are changing dramatically, the student stands in the center of the educational process as an active subject acquiring education in the form of "personal knowledge". Each subject of the educational process is seen as a personality who creates and develops one's own intelligence. Therefore, a truly fundamental knowledge is just the "personal knowledge". In order to form the personal knowledge it is demanded personality oriented training techniques, their development and implementation is the most important link of education modernization.

\section{Acknowledgments}

The authors thank all participants of this study for their kind cooperation.

\section{References}

Bakhtin, G. P. (1989). Fate of Basic Training. Journal of Bulletin of higher education, 2, 124.

Basharin, V. F. (1993). Educational technology: what is it? Journal of Specialist, 3, 173.

Bushes, Y. A. (1990). Continuity of youth training in vocational schools and universities. Saratov. Publisher in Saratov University Press, 180.

Chitalin, N. A. (2005). Multilevel fundamentalization content of vocational training. Kazan: Publishing house "Kazan", 305

Dyachenko, M. I. (1986). Psychological problems Preparedness. Minsk: Publishing house "BSU”, 67.

Elgin, L. S. (2000). Fundamentalizatcija education in the context of sustainable development of society: the totality, the conceptual bases. $\mathrm{PhD}$ Thesis, 256

Fabrikant, V. A. (1978). Physical science and education. Problems of teaching physics. Publishing house "Knowledge", 121

Gutorov, G. S. (1977). Methods and system of work on the relationship of subjects of general education and vocational cycles professional technical schools: Publishing House "High School", 90.

Koldenkova, A. T. (1977). Analysis of the factors in the formation of a professional orientation of students at the technical college students. Journal of Vestnik Leningrad Univ. Ser. Ekonomika, philosophy, and law, 5, 76 
Kondratiev, V. V. (2001). Fundamentalizatcija vocational education specialist at University of Technology. Monograph. Publishing house "KGTU", 152.

Kudryavtsev, A. Y. (1981). On the problem of learning principles. Soviet pedagogy, 110.

Kuzmina, N. V. (1970). Research methods teaching activities: Leningrad State University, 125.

Kuznetsov, V. S. (1994). On the relation between fundamental and professional components in university education. Journal of Higher education in Russia, 4, 87.

Ledneva, O. V. (1990). Social problems of formation of a professional orientation of the person. PhD Thesis, Saratov, 180.

Mukhametzyanova, G. V. (2002). Priority trend of updating the content of humanitarian and fundamental training in the ACT. Journal of "Vocational education", 1, 57

Novikov, A. M. (2007). Principle fundamentalization education. Journal of Specialist, 1, 36

Shapiro, M. I. (1989). Proceedings of the meeting-seminar of heads of departments and leading lecturers on general physics of higher educational institutions of the Central zone. Moscow, 171.

Subetto, A. I. (1995). Fundamentalization problems and sources of the content of higher education: the brink of public policy. Kostroma: Publishing house "KPU", 405

Sukhanov, A. D. (1996). The concept of fundamental nature of higher education and its reflection in GOSah. Journal of Higher education in Russia, 3, 75

Tkachenko, A. S. (1978). Formation of a professional orientation of students of specialized secondary educational institution: dis. ... Candidate of pedagogical sciences. Moscow, 244.

Verbitsky, A. A. (1998). The theory of contextual learning as the basis of educational technologies. The head teacher, 5,100 .

Vlasenko, A. I. (1981). General subjects - professional orientation. Journal of Prof. tehn. Education, 8, 75.

Vorobyov, T. A. (1973). The ratio of professional competence and professional orientation in preparation of the expert. Formation of bases of professional skills in high school. Publishing House of Leningrad. University, 121.

\section{Copyrights}

Copyright for this article is retained by the author(s), with first publication rights granted to the journal.

This is an open-access article distributed under the terms and conditions of the Creative Commons Attribution license (http://creativecommons.org/licenses/by/3.0/). 